\title{
Lifetime risk of diabetes among First Nations and non-First Nations people
}

\author{
Tanvir Chowdhury Turin MBBS PhD, Nathalie Saad MD, Min Jun PhD, Marcello Tonelli MD, Zhihai Ma MSc, \\ Cheryl Carmelle Marie Barnabe MD, Braden Manns MD, Brenda Hemmelgarn MD
}

\begin{abstract}
- Abstract
Background: Lifetime risk is a relatively straightforward measure used to communicate disease burden, representing the cumulative risk of an outcome during the remainder of an individual's life starting from a disease-free index age. We estimated the lifetime risk of diabetes among men and women in both First Nations and non-First Nations populations using a cohort of adults in a single Canadian province.

Methods: We used a population-based cohort consisting of Alberta residents from 1997 to 2008 who were free of diabetes at cohort entry to estimate the lifetime risk of diabetes among First Nations and non-First Nations people. We calculated age-specific incidence rates with the person-year method in 5-year bands. We estimated the sex- and index-agespecific lifetime risk of incident diabetes, after adjusting for the competing risk of death.

Results: The cohort included 70631 First Nations and 2732214 non-First Nations people

aged 18 years or older. The lifetime risk of diabetes at 20 years of age was $75.6 \%$ among men and $87.3 \%$ among women in the First Nations group, as compared with $55.6 \%$ among men and $46.5 \%$ among women in the non-First Nations group. The risk was higher among First Nations people than among non-First Nations people for all index ages and for both sexes. Among non-First Nations people, men had a higher lifetime risk of diabetes than women across all index ages. In contrast, among First Nations people, women had a higher lifetime risk than men across all index ages.

Interpretation: About 8 in 10 First Nations people and about 5 in 10 non-First Nations people of young age will develop diabetes in their remaining lifetime. These populationbased estimates may help health care planners and decision-makers set priorities and increase public awareness and interest in the prevention of diabetes.
\end{abstract}

$\mathrm{D}$ iabetes mellitus is a major health problem worldwide and is associated with increased morbidity, mortality, life expectancy and health care costs. ${ }^{1-4}$ The prevalence of diabetes in Canada has increased more than twofold over the past decade. ${ }^{5}$ Currently, the disease affects almost 2.4 million Canadians, ${ }^{6}$ and its management, along with that of associated complications, costs more than $\$ 9$ billion annually. ${ }^{7}$ The burden of diabetes is particularly high among First Nations people in Canada, with prevalence rates 3-5 times higher than those among nonFirst Nations people. ${ }^{8}$

Reducing the risk of type 2 diabetes will require a broad set of population-based and individual-level interventions that target diabetogenic aspects of lifestyle, as well as social determinants of health. The changes required to achieve these objectives will need buy-in from a wide range of stakeholders. Thus, it will be important to communicate risk in a way that is understood by the general population and by health authorities.
Although estimates of incidence and prevalence provide important information about the burden of a disease in the community, they do not provide adequate information regarding the perspective of risk at the individual level. Lifetime risk (the probability of a disease-free individual developing the disease during his or her remaining lifespan) may be more informative for the general population and for decision-makers. Life-table modelling techniques use incidence and mortality data to estimate the lifetime risk of diabetes. This important assessment of the disease burden of diabetes has been undertaken in a few studies, ${ }^{9-11}$ but it has not been done in Canada. The need for such estimates is particularly relevant given the higher prevalence of diabetes among First Nations people in Canada.

We estimated the lifetime risk of diabetes among men and women in both First Nations and non-First Nations populations using a cohort of adults residing in a single Canadian province.
Competing interests: None declared.

This article has been peer reviewed.

Accepted: May 2, 2016 Online: Sept. 19, 2016

Correspondence to: Tanvir Chowdhury Turin, turin. chowdhury@ucalgary.ca CMAJ 2016. DOI:10.1503/ cmaj.150787 


\section{Methods}

\section{Study population}

All residents of the province of Alberta are eligible for insurance coverage by Alberta Health, and more than $99 \%$ participate in this coverage. We included 2897299 residents aged 18 years or older (1 436324 men and 1460975 women) who were registered with Alberta Health between Apr. 1, 1997, and Mar. 31, 2008. Each person's first encounter date with Alberta Health was considered the study entry date. We excluded those who had diabetes at cohort entry.

\section{Classification of First Nations status}

We determined participants' First Nations status from an indicator variable in the Alberta Health Registry file, which identifies people registered with Aboriginal Affairs and Northern Development Canada under the Indian Act. A person with a First Nations identifier at any time during the study period was classified as First Nations; all other participants were classified as non-First Nations people. ${ }^{12}$ Aboriginal people in Alberta who were not registered within the Indian Act (e.g., unregistered First Nations and Metis) were included in the non-First Nations group. According to the 2011 census, about $52 \%$ of the Alberta Aboriginal population is registered First Nations. ${ }^{13}$

After Ontario and British Colombia, Alberta has the third largest First Nations population among the provinces and territories of Canada. ${ }^{14}$ About half of the population lives on Indian reserves..$^{15}$ More than half of First Nations people in Alberta are under 25 years of age, and less than $5 \%$ are over 64 years old; the median age is 23 years. ${ }^{15}$ Great cultural diversity exists within the Albertan First Nations communities, including a broad range of spoken languages, the most common being Blackfoot, Cree, Chipewyan, Dene, Sarcee and Stoney. ${ }^{15}$

\section{Outcome measure}

Participants were followed for the development of diabetes after their study entry. The diagnosis of diabetes was based on the previously validated National Diabetes Surveillance System definition. ${ }^{16}$ The case definition required 2 or more physician service claims for diabetes (International Classification of Diseases, 9th Revision [ICD-9] code 250) within 2 years, or 1 or more hospital admissions with ICD-9 code 250 (before Mar. 31, 2002) or the equivalent ICD-10 (International Statistical Classification of Disease and Related Health Problems, 10th Revision) codes E10-14 (after Mar. 31, 2002), ${ }^{16}$ selected from all available diagnostic codes from the administra- tive data sources. ${ }^{17}$ This case definition has been reported to have $86 \%$ sensitivity, $97 \%$ specificity and $80 \%$ positive predictive values for identifying individuals with diabetes through administrative data sources. ${ }^{16}$ Death was determined from the Alberta Health Registry file. Participants were followed from their study index date to the occurrence of the study outcome, death, out-migration from Alberta or the end of the study period (Mar. 31, 2009).

\section{Measurement of cohort characteristics}

Socioeconomic status was categorized based on Statistics Canada 2001 and 2006 census data. Median neighbourhood household income (in quintiles) and residency (rural or urban) were identified based on census data closest to the study entry date of the participants..$^{18} \mathrm{~A}$ diagnosis of hypertension was determined based on previously validated criteria. ${ }^{19}$ We identified other comorbid conditions among physician claims and hospital admission records using validated coding algorithms based on the Deyo adaptation (ICD-9, Clinical Modification [ICD-9-CM] data) and the Quan validation (ICD-10 data) of the Charlson Comorbidity Index..$^{20}$

\section{Statistical analysis}

We used age (in years) as the time scale. The index age categories started at age 20 years and increased by decade to age 60 . Risk estimation began at an index age; participants who were younger than the index age of interest at the beginning of the study period entered the analysis when they reached the required age. For example, for risk estimation at an index age of 20 years, participants aged 20 years and older were included; those who were less than 20 years old at cohort entry began contributing to the risk estimation when they attained the age of 20 .

We estimated the cumulative incidence of diabetes conditional on survival to ages 20, 30, 40, 50 and 60 years. We estimated lifetime risk of diabetes accounting for the competing risk of death. We calculated index-age-specific incidence of diabetes and the lifetime risk estimates using a modified technique of survival analysis, ${ }^{21}$ as in prior reported analyses. ${ }^{22,23}$ In contrast to the conventional Kaplan-Meier survival analysis (which considers individuals who die as censored observations), this modified approach considers death as a competing event.

All statistical analyses were performed using SAS version 9.1 (SAS Institute).

\section{Ethics approval}

The Conjoint Health Research Ethics Board of the University of Calgary approved the study. 


\section{Results}

The study cohort included 2802845 participants without a history of diabetes, $70631(2.5 \%)$ of whom had First Nations status (Figure 1). The mean follow-up period was 8.71 (standard deviation 3.84) years. The First Nations participants were younger, generally had a higher prevalence of comorbid conditions and were more likely to be in a lower income quintile (Table 1). During a total follow-up of 23362108.3 person-years for the participants 20 years and older during the study, diabetes developed in 160549 participants. The number of person-years of follow-up and the number of events (diabetes and death) across all age groups are presented in Appendix 1 (available at www.cmaj.ca/lookup/suppl/doi:10.1503/ cmaj.150787/-/DC1).

Table 2 presents the lifetime risk of diabetes as well as the risk over 10-, 20-, 30- and 40-year time horizons among First Nations and non-First Nations men by index age. The lifetime risk of diabetes adjusted for competing risk of death among 20-year-old men was $75.6 \%$ in the First Nations group and $55.6 \%$ in the non-First Nations group. As expected, there was a graded increase in the risk of diabetes over longer time horizons for all index ages in both First Nations and non-First Nations groups. For example, among 20-year-old First Nations men, the risk of diabetes was $1.4 \%, 6.0 \%, 15.4 \%, 31.5 \%, 51.7 \%$ and $68.6 \%$ over the 10-, 20-, 30-, 40-, 50- and 60year time horizons, respectively.

Table 3 presents the short, intermediate and lifetime risks of diabetes among women in the First Nations and non-First Nations groups. Among 20-year-old women, the adjusted lifetime risk was $87.3 \%$ in the First Nations group and $46.5 \%$ in the non-First Nations group. The lifetime risk of diabetes was lower among

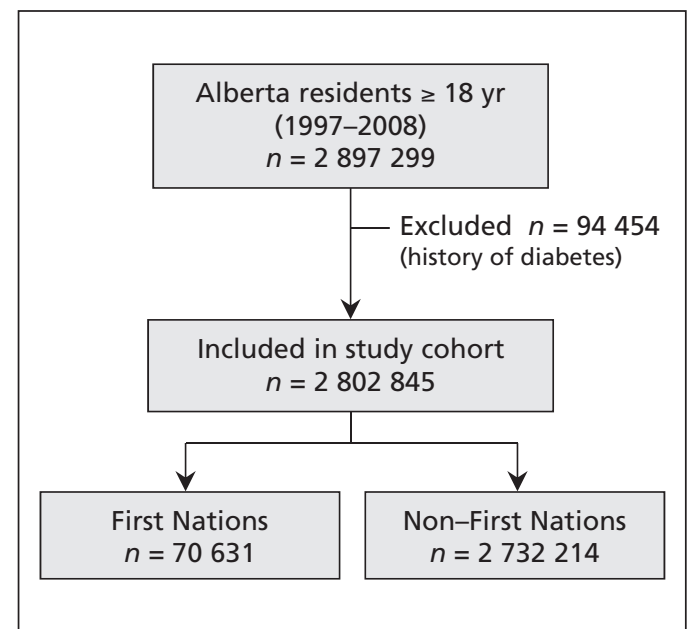

Figure 1: Selection of the study cohort. women than among men in all index age categories in the non-First Nations group. In contrast, First Nations women had a higher lifetime risk of diabetes than First Nations men in all index age categories (Tables 2 and 3). Again, a graded increase in diabetes risk with increasing time horizon was consistently observed among women in both the First Nations and non-First Nations groups (Figure 2).

The lifetime risk estimates of diabetes among men and women by location of residence (urban or rural) are presented in Appendix 2 (available at www.cmaj.ca/lookup/suppl/doi:10.1503/cmaj .150787/-/DC1). The estimates among First Nations men and women were consistently higher than those among their non-First Nations counterparts across both urban and rural locations. In the First Nations group, the lifetime risk of diabetes was notably higher among those living in

Table 1: Baseline characteristics of study participants by First Nations status

\begin{tabular}{|c|c|c|}
\hline \multirow[b]{2}{*}{ Characteristic } & \multicolumn{2}{|c|}{$\%$ of participants* } \\
\hline & $\begin{array}{c}\text { First Nations } \\
n=70631\end{array}$ & $\begin{array}{c}\text { Non-First Nations } \\
n=2732214\end{array}$ \\
\hline Age, yr, mean \pm SD & $34.5 \pm 12.6$ & $40.7 \pm 16.3$ \\
\hline Sex, female & 49.9 & 49.5 \\
\hline \multicolumn{3}{|l|}{ Comorbid condition } \\
\hline Hypertension & 3.9 & 7.5 \\
\hline Cerebrovascular disease & 0.7 & 1.0 \\
\hline Peripheral vascular disease & 0.2 & 0.6 \\
\hline Congestive heart failure & 0.8 & 1.1 \\
\hline Cancer & 1.0 & 1.8 \\
\hline COPD & 17.6 & 9.2 \\
\hline Dementia & 0.2 & 0.5 \\
\hline Myocardial infarction & 0.5 & 0.9 \\
\hline Peptic ulcer disease & 4.8 & 1.9 \\
\hline Rheumatic disease & 1.2 & 0.6 \\
\hline \multicolumn{3}{|l|}{ Location of residence } \\
\hline Rural & 47.7 & 19.3 \\
\hline Urban & 52.3 & 80.7 \\
\hline Unknown & 0.0 & 0.01 \\
\hline \multicolumn{3}{|l|}{ Income quintile } \\
\hline 1 (lowest) & 42.5 & 21.6 \\
\hline 2 & 14.7 & 19.6 \\
\hline 3 & 10.5 & 18.3 \\
\hline 4 & 7.9 & 18.0 \\
\hline 5 (highest) & 9.4 & 17.8 \\
\hline Unknown & 15.1 & 4.71 \\
\hline
\end{tabular}


rural locations than among those in urban areas. This difference was strikingly prominent among women. For example, 20-year-old First Nations women in rural areas had a lifetime risk of $94.2 \%$, as compared with $80.4 \%$ among their counterparts in urban locations. In contrast, nonFirst Nations men and women in urban locations had slightly higher lifetime risks of diabetes than their rural counterparts.

\section{Interpretation}

We estimated the lifetime risk of diabetes among First Nations and non-First Nations people in a population-based cohort of nearly 3 million people from a provincial health registry. The observed probabilities suggest that about 5 in 10 non-First Nations men and women of young age will develop diabetes in their lifetime. The lifetime risk

\begin{tabular}{|c|c|c|c|}
\hline \multirow{2}{*}{$\begin{array}{l}\text { Index } \\
\text { age, yr }\end{array}$} & \multirow[b]{2}{*}{ Time horizon } & \multicolumn{2}{|c|}{ Risk estimate, $\%(95 \% \mathrm{Cl})$} \\
\hline & & First Nations & Non-First Nations \\
\hline \multirow[t]{7}{*}{20} & $10 \mathrm{yr}$ & $1.4(1.2-1.7)$ & $0.6(0.6-0.7)$ \\
\hline & $20 \mathrm{yr}$ & $6.0(5.6-6.4)$ & $2.5(2.4-2.6)$ \\
\hline & $30 \mathrm{yr}$ & $15.4(14.7-16.1)$ & $7.4(7.3-7.5)$ \\
\hline & $40 \mathrm{yr}$ & $31.5(30.3-32.8)$ & $18.1(17.9-18.3)$ \\
\hline & $50 \mathrm{yr}$ & $51.7(49.9-53.6)$ & $33.5(33.3-33.8)$ \\
\hline & $60 \mathrm{yr}$ & $68.6(66.0-71.0)$ & $47.8(47.5-48.1)$ \\
\hline & Lifetime & $75.6(72.6-78.5)$ & $55.6(55.3-55.9)$ \\
\hline \multirow[t]{6}{*}{30} & $10 \mathrm{yr}$ & $4.7(4.3-5.0)$ & $1.9(1.9-1.9)$ \\
\hline & $20 \mathrm{yr}$ & $14.3(13.6-15.0)$ & $6.8(6.7-6.9)$ \\
\hline & $30 \mathrm{yr}$ & $30.8(29.6-32.1)$ & $17.6(17.4-17.7)$ \\
\hline & $40 \mathrm{yr}$ & $51.5(49.6-53.4)$ & 33.1 (32.9-33.4) \\
\hline & $50 \mathrm{yr}$ & $68.6(66.1-71.2)$ & $47.5(47.2-47.8)$ \\
\hline & Lifetime & 75.9 (72.9-78.9) & $55.3(55.0-55.7)$ \\
\hline \multirow[t]{5}{*}{40} & $10 \mathrm{yr}$ & $10.0(9.3-10.6)$ & $4.9(4.9-5.0)$ \\
\hline & $20 \mathrm{yr}$ & $27.1(25.8-28.3)$ & $15.8(15.7-16.0)$ \\
\hline & $30 \mathrm{yr}$ & $48.5(46.6-50.4)$ & $31.5(31.3-31.7)$ \\
\hline & $40 \mathrm{yr}$ & $66.3(63.6-68.9)$ & $46.0(45.7-46.3)$ \\
\hline & Lifetime & 73.8 (70.6-76.9) & $53.9(53.6-54.3)$ \\
\hline \multirow[t]{4}{*}{50} & $10 \mathrm{yr}$ & $18.0(16.8-19.3)$ & $11.1(10.9-11.2)$ \\
\hline & $20 \mathrm{yr}$ & $40.7(38.7-42.7)$ & $27.0(26.8-27.3)$ \\
\hline & $30 \mathrm{yr}$ & $59.5(56.7-62.2)$ & $41.8(41.5-42.1)$ \\
\hline & Lifetime & $67.4(64.0-70.7)$ & $49.9(49.5-50.2)$ \\
\hline \multirow[t]{3}{*}{60} & $10 \mathrm{yr}$ & $24.8(22.8-26.9)$ & 16.7 (16.4-16.9) \\
\hline & $20 \mathrm{yr}$ & $45.4(42.3-48.5)$ & $32.0(31.7-32.3)$ \\
\hline & Lifetime & $54.1(50.4-57.8)$ & $40.4(40.1-40.8)$ \\
\hline
\end{tabular}

was much higher in the First Nations population (about 7 in 10 men and 9 in 10 women).

In our study, men had a higher lifetime risk of diabetes than women of similar age strata in the non-First Nations group. In contrast, women had a higher lifetime risk than men in the First Nations group. This observation likely reflects the fact that the incidence of diabetes is higher among First Nations women than among First Nations men in Canada. ${ }^{24}$ That women in First Nations communities are more likely to be overweight or obese than the men, and at a younger age ${ }^{25}$ would explain this disparity to some extent. Also, there are high rates of gestational diabetes among pregnant Aboriginal women who develop type 2 diabetes later in life. ${ }^{26}$

Irrespective of urban or rural location of residence, we observed a higher lifetime risk of diabetes among First Nations people than among non-First nations people. However, in the First Nations group, the lifetime risk was higher among those living in rural communities than among those in urban areas. This difference was striking among First Nations women. Access to care and geographic factors, which have been identified as important determinants of health for indigenous people, ${ }^{27}$ may be contributing to the higher observed risk. ${ }^{28}$

We also observed that the First Nations group reached a higher risk of diabetes at a much younger age than the non-First Nations group. The cumulative risk of diabetes among young First Nations men overtook the lifetime risk among nonFirst Nations men by about 20 years earlier. Among First Nations women, this happened about 30 years earlier. These findings coupled with the observations that younger people had a higher lifetime risk of diabetes than their older counterparts indicates the importance of early mobilization of preventive measures against the development of diabetes among First Nations people.

Reports of a similar nature were limited to studies in the United States ${ }^{11}$ and Australia. ${ }^{9}$ However, the methodologic differences across these studies hinder direct comparison of the estimates with our results. In the US study, Narayan and associates ${ }^{11}$ used incidence rates and mortality derived from different sources and a Markov chain model to estimate the lifetime risk of diabetes. The authors estimated that the lifetime risk of diabetes among people 40 years of age was about 3 in $10 .{ }^{11}$ They defined diabetes based on selfreported disease status, which might have underestimated true diabetes rates.

In the Austrialian study, Magliano and associates $^{9}$ used the approach of building a multistate life table to estimate the lifetime risk of diabetes in an epidemiologic cohort of 5842 adults. ${ }^{9}$ The authors reported that the lifetime probability of 
diabetes among people 26 years of age was about 3 in $10 .{ }^{9}$ They recognized the potential limitation of using a single oral glucose tolerance test to define diabetes in their study and acknowledged the possibility of underestimation of the true risk.

Our analysis used a cohort of nearly 3 million people from a single Canadian province, and diabetes was defined using administrative data sources. We used a survival analysis approach to estimate the lifetime risk of diabetes, with a special focus on the difference in risk between First Nations by non-First Nations people. We did not identify prior reports that compared estimates of lifetime risk in an Aboriginal population and a contemporaneous non-Aboriginal counterpart.

Although the lifetime risk of diabetes was high in both First Nations and non-First Nations groups, it was higher in the former. These findings are consistent with population-based diabetes reports showing higher incidence and prevalence of diabetes among First Nations people than among non-First Nations people. ${ }^{24,29,30}$ Dyck and associates $^{24}$ reported that the incidence and prevalence of diabetes were more than 4 times higher among First Nations women than among nonFirst Nations women, and more than 2.5 times higher among First Nations men than among nonFirst Nations men. The reasons that have been attributed to these differences include genetic susceptibility, ${ }^{31-34}$ dietary acculturation, ${ }^{34,35}$ adoption of sedentary lifestyle ${ }^{34,36}$ and increasing prevalence of obesity and metabolic syndrome. ${ }^{37-39}$ Overall, the First Nations populations in Canada, and similarly other indigenous groups worldwide, are vulnerable to developing diabetes. It also appears that inequities in the social, cultural, historical, economic and political determinants of health, lack of access to nutritionally adequate food and barriers
Table 3: Age- and sex- specific risk estimates for diabetes among First Nations and non-First Nations women, by index age

\begin{tabular}{|c|c|c|c|}
\hline \multirow{2}{*}{$\begin{array}{l}\text { Index } \\
\text { age, yr }\end{array}$} & \multirow[b]{2}{*}{ Time horizon } & \multicolumn{2}{|c|}{ Risk estimate, $\%(95 \% \mathrm{Cl})$} \\
\hline & & First Nations & Non-First Nations \\
\hline \multirow[t]{7}{*}{20} & $10 \mathrm{yr}$ & $2.8(2.5-3.2)$ & $1.2(1.1-1.2)$ \\
\hline & $20 \mathrm{yr}$ & $9.2(8.6-9.7)$ & $3.5(3.4-3.6)$ \\
\hline & $30 \mathrm{yr}$ & $19.4(18.6-20.2)$ & $7.1(7.0-7.2)$ \\
\hline & $40 \mathrm{yr}$ & $38.6(37.3-40.0)$ & $14.7(14.6-14.9)$ \\
\hline & $50 \mathrm{yr}$ & $60.8(58.7-62.9)$ & $26.0(25.8-26.2)$ \\
\hline & $60 \mathrm{yr}$ & $79.2(76.3-82.2)$ & $38.0(37.8-38.3)$ \\
\hline & Lifetime & $87.3(83.7-90.8)$ & $46.5(46.2-46.8)$ \\
\hline \multirow[t]{6}{*}{30} & $10 \mathrm{yr}$ & $6.4(6.0-6.9)$ & $2.4(2.3-2.4)$ \\
\hline & $20 \mathrm{yr}$ & $16.8(16.0-17.6)$ & $6.0(5.9-6.1)$ \\
\hline & $30 \mathrm{yr}$ & $36.2(34.8-37.6)$ & $13.6(13.5-13.7)$ \\
\hline & $40 \mathrm{yr}$ & $58.6(56.5-60.7)$ & $24.9(24.7-25.1)$ \\
\hline & $50 \mathrm{yr}$ & $77.3(74.3-80.3)$ & $37.0(36.7-37.3)$ \\
\hline & Lifetime & $85.4(81.8-89.0)$ & $45.4(45.1-45.7)$ \\
\hline \multirow[t]{5}{*}{40} & $10 \mathrm{yr}$ & $10.6(9.9-11.3)$ & $3.6(3.6-3.7)$ \\
\hline & $20 \mathrm{yr}$ & $30.5(29.1-31.8)$ & $11.3(11.2-11.4)$ \\
\hline & $30 \mathrm{yr}$ & $53.5(51.3-55.6)$ & $22.6(22.4-22.8)$ \\
\hline & $40 \mathrm{yr}$ & $72.5(69.5-75.6)$ & $34.8(34.5-35.1)$ \\
\hline & Lifetime & $80.9(77.2-84.5)$ & $43.3(43.0-43.6)$ \\
\hline \multirow[t]{4}{*}{50} & $10 \mathrm{yr}$ & $20.6(19.3-21.9)$ & $7.7(7.6-7.9)$ \\
\hline & $20 \mathrm{yr}$ & $44.5(42.2-46.7)$ & $19.2(19.0-19.4)$ \\
\hline & $30 \mathrm{yr}$ & $64.3(61.0-67.5)$ & $31.5(31.2-31.8)$ \\
\hline & Lifetime & $72.9(69.1-76.8)$ & $40.1(39.8-40.4)$ \\
\hline \multirow[t]{3}{*}{60} & $10 \mathrm{yr}$ & $25.5(23.2-27.7)$ & $11.8(11.6-12.0)$ \\
\hline & $20 \mathrm{yr}$ & $46.6(43.1-50.1)$ & $24.4(24.2-24.7)$ \\
\hline & Lifetime & $55.8(51.6-60.0)$ & 33.2 (32.9-33.6) \\
\hline
\end{tabular}

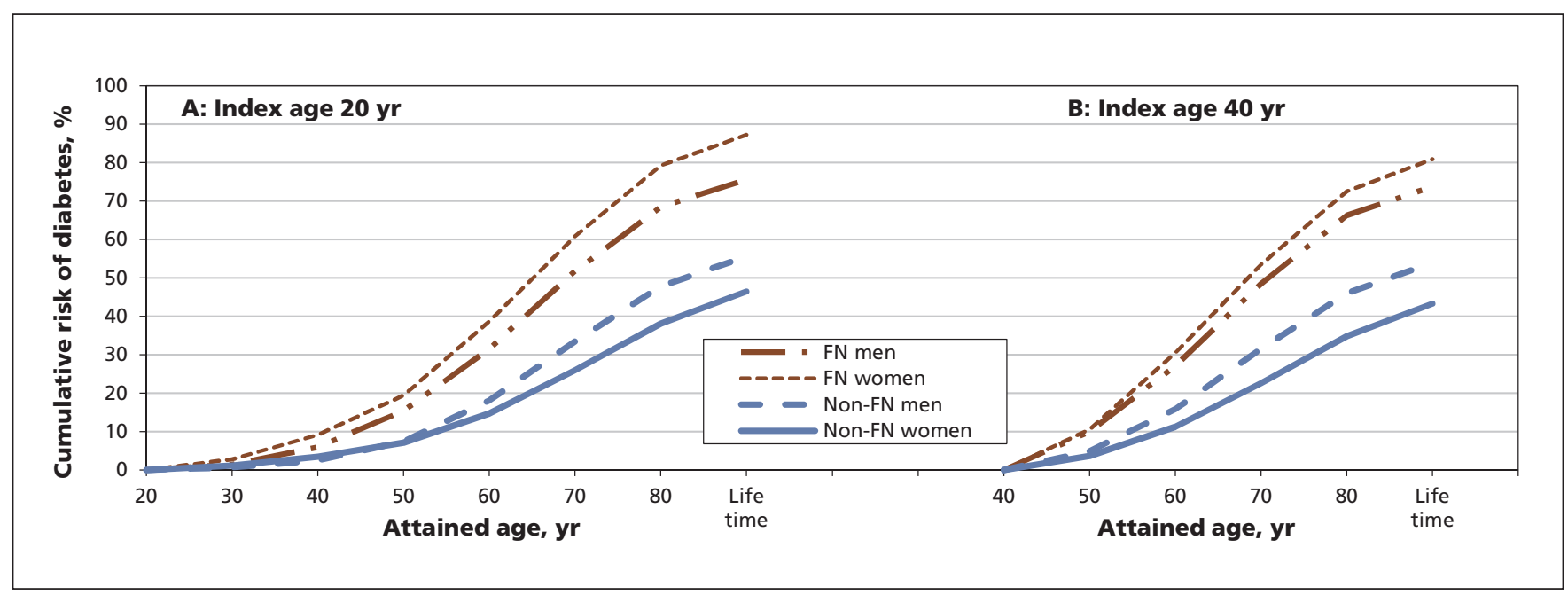

Figure 2: Cumulative risk of diabetes with advancing age among First Nations and non-First Nations men and women at the index age of (A) 20 years and (B) 40 years. FN = First Nations. 
to proper health care play major roles in the diabetes epidemic in indigenous populations..$^{40-43}$

The increase we observed in the cumulative risk of diabetes across the time horizons for all index age categories among both men and women reflected the contribution of the age time scale that has been reported for other chronic diseases. ${ }^{44} 48$ We also observed that the lifetime risk decreased by increasing index age, which is consistent with reports of lifetime risk estimation for other diseases. ${ }^{44-48}$ The decrease in lifetime risk of diabetes with increasing age reflects the shorter life expectancy and period at risk among older participants. Also, at older ages, competing causes of death will increase in importance because older people may not live long enough to develop diabetes, and people susceptible to diabetes might have developed the disease at an earlier age.

From the perspective of public health education, the lifetime risk estimates are beneficial because they are more intuitive than conventional epidemiologic measures such as incidence, prevalence and relative risk. ${ }^{49}$ Problems with statistical numeracy or low quantitative literacy are not uncommon..$^{50}$ Furthermore, innumeracy and difficulties understanding proportions, ratios and relative risks seem to be general barriers to knowledge translation across all user communities in Canada. Indeed, one study found that patients preferred their health risks to be presented in absolute terms and that their lifetime estimate of risk be given in an " $\mathrm{X}$ in 100 " format..$^{51} \mathrm{In}$ addition, merits of reporting lifetime risk estimates have been observed. For instance, the widely publicized lifetime risk of breast cancer among American women (estimated to be 1 in $8[12.6 \%])^{52}$ is believed to have influenced the increase in screening mammography for early disease detection..$^{53}$

Although lifetime risk lacks the detail and precision needed for individual clinical consultation, the lifetime estimates presented in our study offer a useful and understandable summary of risk in a population. This will be particularly relevant to help researchers and policy-makers appreciate the population burden of diabetes.

\section{Limitations}

The strengths of our study include the use of a population-based cohort and data that encompassed diabetes and mortality. However, our reported estimates need to be interpreted in light of the limitations of this type of methodology ${ }^{47,52,54-57}$ First, lifetime risk estimates are population based and reflect average individuals in a population. Although they serve as general guidelines, lifetime risk estimates therefore have only restricted prognostic utility at the patient level, where the lifetime risk would be influenced by individual risk factors for diabetes.
Second, lifetime risk estimates assume a fixed age and demographic structure for the general population, as well as stable diabetes incidence rates and mortality. Because studies suggest that the incidence and prevalence of diabetes is increasing over time, the lifetime risk of diabetes may be even higher than reported here. Moreover, the temporal trends in life expectancy, sensitivity of diagnostic tests and the prevalence of risk factors could also alter the lifetime risk estimates of diabetes. Also, our results are based on population-based data from Alberta; they may not be generalizable to other provinces in Canada.

Third, it was not possible for us to recognize unregistered First Nations people, which may caused misclassification of some individuals in the non-First Nations group. Nonetheless, given that most of the First Nations population in Alberta is registered and given the size of the non-First Nations population in our study, we expect this potential misclassification to have minimal impact on the study estimates.

Fourth, we did not differentiate between type 1 , type 2 and gestational diabetes. However, the major form of diabetes in the population is type 2 diabetes, which accounts for 90\%-95\% of diabetes cases in Canada. ${ }^{6}$

\section{Conclusion}

The observed probabilities indicate that $75.6 \%$ of First Nations men and $87.3 \%$ of First Nations women of young age will develop diabetes in their lifetime. The corresponding risk among non-First Nations people is about $55.6 \%$ and $46.5 \%$, respectively. These measures can be used both in assisting health care planners and decision-makers to set priorities and in increasing public awareness and interest in primary prevention initiatives against diabetes.

\section{References}

1. Wild S, Roglic G, Green A, et al. Global prevalence of diabetes: estimates for the year 2000 and projections for 2030. Diabetes Care 2004;27:1047-53.

2. Zimmet P, Alberti K, Shaw J. Global and societal implications of the diabetes epidemic. Nature 2001;414:782-7.

3. Turin TC, Murakami Y, Miura K, et al. Diabetes and life expectancy among Japanese - NIPPON DATA80. Diabetes Res Clin Pract 2012;96:e18-22.

4. American Diabetes Association. Economic costs of diabetes in the U.S. in 2012. Diabetes Care 2013;36:1033-46.

5. Johnson JA. Alberta diabetes atlas 2009. Edmonton: Institute of Health Economics; 2009.

6. Diabetes in Canada: facts and figures from a public health perspective. Ottawa: Public Health Agency of Canada; 2011. Available: www.phac-aspc.gc.ca/cd-mc/publications/diabetes-diabete/ facts-figures-faits-chiffres-2011/index-eng.php (accessed 2014 Nov. 15).

7. Simpson SH, Corabian $\mathrm{P}$, Jacobs $\mathrm{P}$, et al. The cost of major comorbidity in people with diabetes mellitus. CMAJ 2003;168:1661-7.

8. First Nations \& Inuit Health: diabetes. Ottawa: Health Canada; 2013. Available: www.hc-sc.gc.ca/fniah-spnia/diseases-maladies/ diabete/index-eng.php (accessed 2014 Nov. 15).

9. Magliano DJ, Shaw JE, Shortreed SM, et al. Lifetime risk and projected population prevalence of diabetes. Diabetologia 2008; 51:2179-86. 
10. Narayan KM, Boyle JP, Thompson TJ, et al. Effect of BMI on lifetime risk for diabetes in the US. Diabetes Care 2007;30:1562-6.

11. Narayan KM, Boyle JP, Thompson TJ, et al. Lifetime risk for diabetes mellitus in the United States. JAMA 2003;290:1884-90.

12. Population by selected ethnic origins, by province or territory (2006 census) (Canada). Ottawa: Statistics Canada; 2006.

13. Aboriginal peoples of Canada: First Nations people, Métis and Inuit. Ottawa: Statistics Canada; 2011. Available: www12.statcan. gc.ca/nhs-enm/2011/as-sa/99-011-x/99-011-x2011001-eng.cfm (accessed 2015 July 1 ).

14. Aboriginal peoples in Canada: First Nations people, Métis and Inuit: National Household Survey, 2011. Ottawa: Statistics Canada; 2013. Available: www12.statcan.gc.ca/nhs-enm/2011/as -sa/99-011-x/99-011-x2011001-eng.pdf (accessed 2016 Feb. 21).

15. Lachance N, Hossack N, Wijayasinghe C, et al. Health determinants for First Nations in Alberta. Ottawa: Health Canada; 2009. Available: http://publications.gc.ca/collections/collection_2011/ sc-hc/H34-217-2010-eng.pdf (accessed 2016 Mar. 26).

16. Hux JE, Ivis F, Flintoft V, et al. Diabetes in Ontario: determination of prevalence and incidence using a validated administrative data algorithm. Diabetes Care 2002;25:512-6.

17. Hemmelgarn BR, Clement F, Manns BJ, et al. Overview of the Alberta Kidney Disease Network. BMC Nephrol 2009;10:30.

18. Hemmelgarn BR, James MT, Manns BJ, et al. Rates of treated and untreated kidney failure in older vs younger adults. JAMA 2012;307:2507-15.

19. Quan H, Khan N, Hemmelgarn BR, et al.; Hypertension Outcome and Surveillance Team of the Canadian Hypertension Education Programs. Validation of a case definition to define hypertension using administrative data. Hypertension 2009;54:1423-8.

20. Quan H, Sundararajan V, Halfon P, et al. Coding algorithms for defining comorbidities in ICD-9-CM and ICD-10 administrative data. Med Care 2005;43:1130-9.

21. Beiser A, D'Agostino RB Sr, Seshadri S, et al. Computing estimates of incidence, including lifetime risk: Alzheimer's disease in the Framingham Study. The Practical Incidence Estimators (PIE) macro. Stat Med 2000;19:1495-522.

22. Vasan RS, Beiser A, Seshadri S, et al. Residual lifetime risk for developing hypertension in middle-aged women and men: The Framinham Heart Study. JAMA 2002;287:1003-10.

23. Driver JA, Djoussé L, Logroscino G, et al. Incidence of cardiovascular disease and cancer in advanced age: prospective cohort study. BMJ 2008;337:a2467.

24. Dyck R, Osgood N, Lin TH, et al. Epidemiology of diabetes mellitus among First Nations and non-First Nations adults. CMA. 2010;182:249-56.

25. Bruce SG, Riediger ND, Zacharias JM, et al. Obesity and obesity-related comorbidities in a Canadian First Nation population. Prev Chronic Dis 2011;8:A03.

26. Dyck R, Klomp H, Tan LK, et al. A comparison of rates, risk factors, and outcomes of gestational diabetes between aboriginal and non-aboriginal women in the Saskatoon health district. Diabetes Care 2002;25:487-93.

27. Martens PJ, Martin BD, O'Neil JD, et al. Diabetes and adverse outcomes in a First Nations population: associations with healthcare access, and socioeconomic and geographical factors. Can J Diabetes 2007;31:223-32.

28. Shah BR, Gunraj N, Hux JE. Markers of access to and quality of primary care for aboriginal people in Ontario, Canada. Am J Public Health 2003;93:798-802.

29. Green C, Blanchard JF, Young TK, et al. The epidemiology of diabetes in the Manitoba-registered First Nation population: current patterns and comparative trends. Diabetes Care 2003;26:1993-8.

30. Hemmelgarn BR, Toth EL, King M, et al. Diabetes in First Nations people. In: Johnson JA, editor. Alberta diabetes atlas 2007. Edmonton: Institute of Health Economics; 2007:127-40.

31. Hegele RA, Cao H, Hanley A, et al. Clinical utility of HNF1A genotyping for diabetes in aboriginal Canadians. Diabetes Care 2000;23:775-8.

32. Triggs-Raine BL, Kirkpatrick RD, Kelly SL, et al. HNF-1alpha G319S, a transactivation-deficient mutant, is associated with altered dynamics of diabetes onset in an Oji-Cree community. Proc Natl Acad Sci U S A 2002;99:4614-9.

33. Sellers EA, Triggs-Raine B, Rockman-Greenberg C, et al. The prevalence of the HNF-1 $\alpha$ G319S mutation in Canadian aboriginal youth with type 2 diabetes. Diabetes Care 2002;25:2202-6.

34. Young TK, Reading J, Elias B. Type 2 diabetes mellitus in Canada's First Nations: status of an epidemic in progress. CMAJ 2000;163:561-6.

35. Young TK. The health of Native Americans: toward a biocultural epidemiology. New York: Oxford University Press; 1994 $145-68$

36. Ng C, Young TK, Corey PN. Associations of television viewing, physical activity and dietary behaviours with obesity in aboriginal and non-aboriginal Canadian youth. Public Health Nutr 2010;13:1430-7.

37. Lix LM, Bruce S, Sarkar J, et al. Risk factors and chronic conditions among Aboriginal and non-Aboriginal populations. Health Rep 2009;20:21-9.

38. Liu J, Young TK, Zinman B, et al. Lifestyle variables, nontraditional cardiovascular risk factors, and the metabolic syndrome in an Aboriginal Canadian population. Obesity (Silver Spring) 2006; 14:500-8

39. Pollex RL, Hanley AJ, Zinman B, et al. Metabolic syndrome in aboriginal Canadians: prevalence and genetic associations. Atherosclerosis 2006;184:121-9.

40. Gracey M, King M. Indigenous health part 1: determinants and disease patterns. Lancet 2009;374:65-75.

41. Ghosh H. Urban reality of type 2 diabetes among First Nations of eastern Ontario: western science and indigenous perceptions. J Global Citizenship Equity Educ 2012;2:158-81.

42. Ghosh H, Gomes J. Type 2 diabetes among Aboriginal peoples in Canada: a focus on direct and associated risk factors. Pimatisiwin 2011;9:245-75.

43. First Nations Regional Longitudinal Health Survey (RHS) 2002/03: results for adults, youths and children living in First Nations communities. Ottawa: First Nations Centre; 2005. Available: http://fnigc.ca/sites/default/files/ENpdf/RHS_2002 rhs2002-03-technical_report.pdf (accessed 2016 Feb. 21).

44. Turin TC, Kokubo Y, Murakami Y, et al. Lifetime risk of acute myocardial infarction in Japan. Circ Cardiovasc Qual Outcomes 2010;3:701-3

45. Turin TC, Kokubo Y, Murakami Y, et al. Lifetime risk of stroke in Japan. Stroke 2010;41:1552-4.

46. Seshadri S, Beiser A, Kelly-Hayes M, et al. The lifetime risk of stroke. Stroke 2006;37:345-50.

47. Lloyd-Jones DM, Larson MG, Beiser A, et al. Lifetime risk of developing coronary heart disease. Lancet 1999;353:89-92.

48. Turin TC, Tonelli M, Manns BJ, et al. Lifetime risk of ESRD. $J$ Am Soc Nephrol 2012;23:1569-78.

49. Edwards A, Elwyn G, Mulley A. Explaining risks: turning numerical data into meaningful pictures. BMJ 2002;324:827-30.

50. Schwartz LM, Woloshin S, Welch HG. Risk communication in clinical practice: putting cancer in context. J Natl Cancer Inst Monogr 1999;(25):124-33.

51. Fortin JM, Hirota LK, Bond BE, et al. Identifying patient preferences for communicating risk estimates: a descriptive pilot study. BMC Med Inform Decis Mak 2001;1:2.

52. Feuer EJ, Wun LM, Boring CC, et al. The lifetime risk of developing breast cancer. J Natl Cancer Inst 1993;85:892-7.

53. National Center for Health Statistics. Healthy people 2000 review, 1995-96. Hyattsville (MD): Public Health Service; 1996.

54. Seshadri S, Wolf P, Beiser A, et al. Lifetime risk of dementia and Alzheimer's disease. Neurology 1997;49:1498-504.

55. Turin TC, Hemmelgarn BR. Long-term risk projection and it application to nephrology research. J Nephrol 2012;25:441-9.

56. Turin TC, Rumana N, Okamura T. Residual lifetime risk of cardiovascular diseases in Japan. J Atheroscler Thromb 2011;18:443-7.

57. Cummings SR, Black DM, Rubin SM. Lifetime risks of hip, Colles', or vertebral fracture and coronary heart disease among white postmenopausal women. Arch Intern Med 1989;149:2445-8.

Affiliations: Department of Family Medicine (Turin), Department of Community Health Sciences (Turin, Manns, Hemmelgarn), Institute of Public Health (Turin, Manns, Hemmelgarn) and Department of Medicine (Saad, Jun, Tonelli, Ma, Barnabe, Manns, Hemmelgarn), University of Calgary, Calgary, Alta.

Contributors: Tanvir Turin and Brenda Hemmelgarn contributed to the study concept and design. Tanvir Turin and Zhiha Ma performed the data analysis. Tanvir Turin, Marcello Tonelli, Braden Manns and Brenda Hemmelgarn interpreted the results. Nathalie Saad, Min Jun and Cheryl Barnabe contributed to the interpretation and contextualization of the results. Tanvir Turin drafted the manuscript, and Nathalie Saad, Min Jun, Cheryl Barnabe, Marcello Tonelli, Braden Manns, Zhihai Ma and Brenda Hemmelgarn revised it critically for important intellectual content. All of the authors approved the final version to be published and agreed to act as guarantors of the work.

Acknowledgement: This study is based in part on data provided by Alberta Health and Alberta Health Services. The interpretation and conclusions are those of the researchers and do not represent the views of the Government of Alberta. 